\title{
Em Tema de Usufruto em Direito Romano
}

\author{
Sara Mazzanti Corrêa \\ (Pós-graduanda pela Universidade de São Paulo)
}

\begin{abstract}
RESUMO: 1. Cícero relata a disputa entre os juristas republicanos Publius Mucius Scaevola, Manius Manilius e M. Iunius Brutus, com relação ao fato de ser considerado fruto o parto da escrava dada em usufruto. 2. Prevalência da tese de Brutus, segundo a qual o filho da escrava pertence ao nú-proprietário, não recebendo tratamento igual ao dos frutos. 3. No Digesto, o princípio estabelecido por Brutus vem mencionado nos fragmentos de Gaio (2 rer. cott., D. 22.1.28.1 = I. 2.1.37) e Ulpiano (17 ad Sab., D. 7.1.68 pr.). 4. A motivação dada por Gaio para o fato de não ser considerado fruto o partus ancillae denota um fundamento de ordem filosరfica. 5. A motivação dada por Ulpiano, por outro lado, apesar do aparente motivo filos 6 fico, apresenta uma nítida coloração de ordem econômica, que em parte se explica pela grande crise do III século d.C. 6. Entretanto, não se conhece exatamente os termos nos quais Brutus elaborou a sua tese. Isso nos permite aventar a hip6tese de que o princípio partus ancillae in fructu non est teria sofrido a influência de fatores de ordem-econômica, dado o grande valor patrimonial dos escravos.
\end{abstract}

RIASSUNTO: 1 . Cicerone riporta la disputa tra i giuristi Plubius Mucius Scaevola, Manius Manilius e M.Iunius Brutus, per quanto riguarda il fatto di considerarsi frutto il parto della schiava data in usufrutto. 2. E prevalsa la tesi di Brutus, secondo cui il figlio della schiava spetta al nudo proprietario, e così non viene annoverato fra i frutti. 3 . Nel Digesto, il principio formulato da Brutus viene ammesso nei passi di Gaio (2 rer. cott., D. 22.1.28.1 = I. 2.1.37) ed Ulpiano (17 ad Sab., D. 7.1.68 pr.). 4. La motivazione data da Gaio al fatto di non venire annoverato fra i frutti il partus ancillae ha un fondamento di carattere filosofico. 5. Dall'altra parte, la motivazione presentata da Ulpiano, nonostante l'apparente motivo filosofico, ha una colorazione di ordine economica, che si potrebbe spiegare in base all'analisi della grande crise economia del III sec. d.C. 6. II problema principale riguarda la mancata motivazione di Brutus al principio da lui determinato, cioe che il partus ancillae in fructu non est, non ne facendo qualsiasi riferimento le fonti.

(*) Gostaria de agradecer ao Prof. Luigi Capogrossi-Colognesi, da Universidade de Roma "La Sapienza", bem como ao Prof. Eduardo C. Silveira Marchi, da Universidade de São Paulo, a atenção dispensada durante a redação deste trabalho. $O$ meu agradecimento sincero também ao Dr. Giunio Rizzelli, pelo seu incentivo constante.

Roma, dezembro de 1987.

Trabalho apresentado na USP em 23 de abril de 1989. 
Cícero, em um passo do De finibus (1.4.12), relata a famosa disputa entre os juristas do II século a.C., Publius Mucius Scaevola, Manius Manilius e M. Iunius Brutus, com relação ao fato de ser considerado fruto o parto da escrava (partus ancillae) dada em usufruto, assim como deveria ser segundo a regra geral:

An, partus ancillae sitne in fructu habendus, disseretur inter principes civitatis, P. Scaevolam Maniumque Manilium, ab iisque $M$. Brutus dissentiet (quod et acutum genus est et ad usus civium non inutile, nosque ea scripta reliquaque eiusdem generis et legimus libenter et legemus),

O debate tomou relevância devido a importância dos três juristas em questão, dado que eram homens políticos, homens de Estado de primeiro plano ${ }^{(1)}$. Pompônio na realidade os considera "fundadores" do ius civile (qui fundaverunt ius civile) ${ }^{(2)}$.

Publius Mucius era um membro da gens Mucia(3), foi pretor em 136

(1) Cfr. J.C. DUMONT, Servus. Rome et l'esclavage sous la Républic, École Française de Rome, Palais Farnèse, 1987, p. 103.

(2) Pomp. sing. ench., D. 1.2.2.39. Cfr. M. TALAMANCA, Costruzione Giuridica e strutture sociali fino a Quinto Mucio, in "Società romana e produzione schiavistica, III. Modelli etici, diritto e trasformazioni sociali”, Bari, 1981, p. 21. Sobre os três juristas em questão, cfr. também M. BRETONE, Publius Mucius et Brutus et Manilius, qui fundaverunt ius civile (D. 1.2.2.39), in "La critica del testo. Atti del secondo congresso internazionale della Società Italiana di Storia del Diritto", Florença 1971, p. 103 ss. e M. BRUTTI, Manio Manilio, Giunio Bruto e Publio Mucio Scaevola, in "Lineamenti di storia di diritto romano", organizado por M. TALAMANCA, Milão, 1979, p. 339 ss.

(3) F. SCHULZ, Roman legal science, Oxford, 1953, 41: outros dois juristas importantes pertencentes a gens Mucia eram P. Licinius Crassus Mucianus e Q. Mucius Scaevola, pontifex, sendo que com este último se atinge "the climax and the end of the pontifical science of private law". Cfr. sobre o mesmo assunto a recente obra de A. SCHIAVONE, Giuristi e nobili nella Roma repubblicana, Roma-Bari, 1987, p. 3 ss. 
a.C., exerceu o consulado no ano 113 a.C. e foi pontifex maximus em 130 a.C. Já Manius Manilius pertencia à classe dos juristas não pontífices, tendo subido ao consulado em 149 a.C. ${ }^{(4)}$. Iunius Brutus exerceu a pretura em época incerta, em torno do ano de 140 a.C., sendo que desenvolveu um grande trabalho como jurista. As fontes nos informam que a sua obra De iure civili foi escrita em forma de diálogo, tendo como interlocutor seu filho ${ }^{(5)}$.

Publius Mucius, Manius Manilius e Brutus foram juristas que viveram em um período de grande fermento social. Período que faz iniciar a crise da República (133, ano do consulado de Publius Mucius, é na realidade também ano em que Tibério Graco assume o tribunato).

A discussão entre os juristas nasce no âmbito do usufruto, com relação a quem deveriam pertencer os filhos nascidos de uma escrava, a qual fosse objeto da relação jurídica. Brutus é da opinião de que esses filhos pertencem ao núproprietário, não recebendo tratamento igual ao dos frutos. P. Mucius e M. Manilius afirmam ao invés que o parto é de ser atribuído ao usufrutuário, raciocinando provavelmente no sentido de que, sendo o escravo uma res, deve seguir a regra geral do usufruto ${ }^{(6)}$ (as fontes, contudo, não se referem aos termos, nos quais basearam tais juristas suas argumentaçōes).

Do passo de Cícero resulta que os pareceres dos três juristas tinham sido legados à tradição escrita, devendo provavelmente fazer parte de suas obras literárias $^{(7)}$ : quod et acutum genus est et ad usus civium non inutile, nosque ea scripta reliquaque eiusdem generis et legimus libenter et legemus.

(4) M. Manilius escrevia sob a forma de coleção de fórmulas, isto é, coleção de contratos, testamentos, ações e defesas precedentes (cfr. SCHULZ, op. cit., 155). Segundo J. LINDERSKY, Partus ancillae. A vetus quaestio in the light of a new inscription, in Labeo 33 (1987), p. 194, Manius Manilius era ainda vivo e ativo em 129 a.C., ano no qual ambienta Cícero o diálogo De republica - diálogo esse que Cícero imagina que se sucedeu entre Scipio Aemilianus, Lelius, Philus, Manilius, Q. Tubero, P. Rutilius, Fannius e Scaevola (cfr. E. BRÉGUEH, Cicéron. La Republique, I, Paris, 1980, p. 16 ss.).

(5) Sobre a forma literária de Brutus como colloquium scholasticum e sua obra, cfr. SCHULZ, op. cit., p. 92 e 327.

(6) TALAMANCA, op. cit., 21.

(7) Cfr. LENEL, Palingenesia iuris civilis, I, Lipsiae, 1889 (Graz 1960), p. 78, 590 e 755: com relação a Brutus e Manilius o autor aponta que ambos fizeram referência ao objeto da controvérsia em obra literária, sendo os nomes dessas obras, contudo, desconhecidos. Com relação a P. Mucius, LENEL não traz nenhuma notícia sobre qualquer obra literária na qual o jurista tenha mencionado tal assunto. 
É do passo de Ulpiano (17 ad Sab., D. 7.1.68 pr.) que sabemos que prevaleceu a opinião de Brutus (Bruti sententia optinuit). Um problema que se coloca, contudo, é o saber quando tal entendimento foi acolhido, sem controvérsia, pelos juristas. Já ao tempo de Ulpiano, sendo ele o jurista mais recente que nos dá notícia do debate, certamente tal problemática não suscitava mais discussão, pois refere-se "a uma velha questão" (vetus quaestio), ou seja, ao passado, resolvida em favor da opinião de Brutus. Também o testemunho de Gaio (2 rer. cott., D. 22.1.28.1) decisivamente não deixa nenhuma dúvida quanto ao fato do partus ancillae não pertencer ao usufrutuário. Cícero, por outro lado, traz somente notícia da discussão, sem mencionar o resultado. Arangio-Ruiz é da opinião de que na época em que Cícero escreveu sua obra De finibus (45 a.C.), a questão referente ao partus ancillae ainda permanecia aberta, "onde ben avrebbe potuto un giudice contemporaneo di Cicerone decidere in senso favorevole alla pretesa dell'usufruttuario"(8). Watson, contudo, é radicalmente contra. Segundo esse autor Cícero, quando escreveu sua obra, estava interessado em filosofia, e não em direito. Sendo assim, qual decisāo havia prevalecido não era importante ${ }^{(9)}$. Razão tem Watson, quando diz que Cícero tinha em mente uma obra filosófica, porém se deve notar que, quando o orador relata a disputa entre os juristas republicanos, diz que tal argumento interessa também à ordem civil (et ad usus civium non inutile).

Recentemente um artigo de Lindersky reabre a discussão sobre esse ponto de divergência entre os romanistas citados. Lindersky é do mesmo parecer de Arangio-Ruiz e sua tese, segundo a qual, ainda no tempo de Augusto, a doutrina predominante era a de P. Mucius e Manilius, é fundamentada com base em uma inscrição epigráfica encontrada em Regium, na Itália, e publicada em $1963^{(10)}$.

Tal inscrição diz respeito à manumissão de três escravos: Thiasus, seu filho Celus e a mãe deste último, cujo nome não se é possível ler na inscrição. Thiasus e Celus teriam sido alforriados por Júlia, filha de Augusto, por volta do ano $2^{2}$ a.C., já que integravam o peculium que este lhe havia destinado, quando a ela foi imposta a pena de exílio na ilha de Pandateria, por haver cometido

(8) V. ARANGIO-RUIZ, Cicerone Giurista, in "Ciceroniana. Rivista di studi Ciceroniani”, dirigida por V. PALADINI, I-II, Roma, 1959, p. 10.

(9) A. WATSON, The law of property in the later roman republic, Oxford, 1968, p. 215. No mesmo sentido: TALAMANCA, op. cit., 320.

(10) Tal inscrição encontra-se publicada em L'année épigraphique, 1975 [1978], p. 75, sob no 289:

C(aius) Iulius Iuliae divi / Aug(usti) f(iliae) l(ibertus) Celos [si]bi et / C(aio) Iulio Iul[iae divi A]ug(usti) f(iliae) l(iberto) / Thiaso patr[i, sexuir(o) a]ug(ustali), / [et Iu]liae divai Au[gustae l(ibertae)] matr[i], / ex testamen[to]. 
adultério. A māe de nome desconhecido teria, contudo, sido alforriada por Lívia, esposa de Augusto e madrasta de Júlia, o que faz supor que essa escrava era de sua propriedade.

Lindersky constrói sua teoria com base em uma suposição: que Lívia teria enviado sua escrava a viver na casa de Júlia e que esta gozava do usufruto da mesma. Thiasus e essa escrava ter-se-iam unido e de tal união teria nascido o filho Celus ${ }^{(11)}$. Nesse caso, de acordo com a doutrina de Brutus sobre o partus ancillae, esse filho deveria tornar-se propriedade de Lívia, que era a domina da mãe. Mas, como foi ele manumitido por Júlia, a propriedade sobre ele claramente passou à usufrutuária, situação essa conforme a teoria de P. Mucius e Manilius.

Reforça, por fim, o autor o seu ponto de vista, tomando um passo das Instituiçōes de Gaio (II, 50), que considera escusável o fato de o usufrutuário de uma escrava alienar os seus partos, por crer que eles lhe pertencem, assim como as crias dos animais. Segundo Gaio o usufrutuário não comete furto: si is, ad quem ancillae ususfructus pertinet, partum etiam suum esse credens vendiderit aut donaverit, furtum non committitur,...

Sabemos, contudo, ainda de Ulpiano (17 ad Sab., D. 7.1.68.1) que um problema semelhante se discutia nos primeiros anos do principado, com relação ao fetus pecorum e que Sabinus e Cassius resolveram no sentido de que esse pertencia ao usufrutuário. Assim, a decisão foi em sentido contrário àquela do partus ancillae: fetus tamen pecorum Sabinus et Cassius opinati sunt ad fructuarium pertinere. As fontes, contudo, não trazem nenhum testemunho sobre a posição desses mesmos juristas, relacionado com o problema do partus ancillae.

No Digesto, o princípio estabelecido por Brutus vem mencionado nos passos de Gaio e Ulpiano ${ }^{(12)}$. O passo de Gaio (2 rer. cott., D. 22.1.28.1 = I. 2.1.37) diz que o parto da escrava deve pertencer ao proprietário porque parecia absurdo que o homem fosse considerado fruto, já que a natureza produz todos os frutos em função do homem:

Partus vero ancillae in fructu non est itaque ad dominum proprietatis pertinet: absurdum enim videbatur hominem in fructu esse, cum omnes fructus rerum natura hominum gratia comparaverit.

(11) Segundo nossa opiniāo, a teoria construída pelo autor força um pouco a intepretação do conteúdo da inscriçāo, retirando dela mais do que realmente diz.

(12) Cfr. Ulp. 15 ad ed., D. 5.3.27 pr.; 17 ad Sab., D. 7.1.68 pr.; 42 ad Sab., 47.2.48.6 e Gai. 2 rer. cott., D. 22.1.28.1 = I. 2.1.37; 2 rer. cott., D. 41.3.36.1 = II.50. 
Segundo Ulpiano (17 ad. Sab., D. 7.1.68 pr.) $)^{(13)}$ o parto da escrava deve pertencer ao nú-proprietário porque "o homem não pode ser considerado fruto do próprio homem":

Vetus fuit quaestio, an partus ad fructuarium pertineret: sed Bruti sententia optinuit fructuarium in eo locum non habere: neque enim in fructu hominum homo esse potest. Hac ratione nec usum fructum in eo fructuarius habebit.

Algumas considerações de ordem conceitual, contudo, se fazem necessárias para a compreensão dos passos acima citados.

A palavra partus vem usada pelos juristas com três significados diversos, sempre se referindo ao ser humano: é usada para indicar a pessoa já nasci$\mathrm{da}^{(14)}$; é usada para indicar o concebido, ainda não nascido, isto é, o nascituro(15); e por fim, pode indicar o parto em si, entendido como o ato de dar a $\mathrm{luz}^{(16)}$. O parto dos animais, entretanto, geralmente vem indicado com a palavra fetus ${ }^{(17)}$.

Com relação a ser ou não considerado "fruto" o parto da escrava, indiscutivelmente o termo "fruto" neste caso corresponde aquele de "fruto natu-

(13) Cfr. Ulp. 42 ad Sab., D. 47.2.48.6.

(14) Com relação às fontes jurídicas, v. por exemplo, Ulp. 24 ad ed., D. 25.4.1.1 (post editum plane partum a muliere) e Paul. 19 resp., D. 1.5.12.

(15) Paul. sing. port., D. 1.5.7 e Marcell. 28 dig., D. 11.8.2.

(16) Tryph. 10 disp., D. 1.5.15 e Ulp. 41 ad ed., D. 37.9.1.19. Encontramos esses mesmos significados acima citados (notas 14 e 15) da palavra partus também na literatura nâo jurídica: com relação ao ser já nascido cfr. Plin. n.h., 8.66, referindo-se aqui, contudo, aos animais (coitus verno aequinoctio bimo utrimque vulgaris, sed a trimatu firmior partus) e A. ERNOUT - A. MEILLET, Dictionnaire étymologique de la Iangue latine, Paris, 5 e., 1979, p. 483; no sentido de nascituro cfr. Flor. 1.38.2 (partus gravidarum mulierum extorquere tormentis); e por último, indicando o momento de dar a luz, cfr. Cic. Cluent. 11.31 (nam cum esset gravida Auria, fratis uxor, et iam appropinquare partus putaret).

(17) Partus nas fontes literárias pode corresponder a fetus (cfr. Cic. Tusc. 5.79: Bestiae pro suo ita propugnant ut vulnera excipiant). Algumas vezes partus vem usado nas fontes jurídicas com referência também aos animais (cfr. por exemplo, Ulp. 15 ad ed., D. 5.3.25.20). Sobre a distinção mais detalhada sobre fetus e partus, v. V. BASANOFF, Partus ancillae, Paris, 1929, 155. 
ral"(18), como, por exemplo, compreendem-se entre os frutos dos animais, as crias, o leite, o pêlo e a lã (Gai. 2 rer. cott., D. 22.1.28 pr.: in pecudum fructu etiam fetus est sicut lac et pilus et lana,....).

E é essa condição de fruto natural que os juristas citdos se recusam a conferir ao escravo. Ambos os passos se justificam afirmando a condição de homo do servo: absurdum enim videbatur hominem in fructu esse, cum omnes fructus rerum natura hominum gratia comparaverit e neque enim in fructu hominis homo esse potest.

Gaio, na verdade, ao fazer a summa divisio de iure personarum insere a categoria dos escravos dentro daquela mais ampla que é a dos "homens", colocando-as lado a lado com a categoria dos homens livres: quod omnes homines aut liberi sunt aut servi (I. 9). Os homens livres, portanto, e os escravos são espécies diversas do gênero "pessoa". O conceito de homo (homem) em geral coincide com aquele de persona ${ }^{(19)}$. Persona aqui não tem o significado de

(18) Segundo BRETONE, La nozione romana di usufrutto. Dalle origini a Diocleziano, Nápoles, 1962, I, 37 ss., no período compreendido entre a época de Plauto e a época de Céro, fructus designa o "fruto em senso natural", máxime os produtos agrícolas individualmente contados, ou também a colheita no seu conjunto e os produtos dos animais. Mais amplamente o termo indica a renda que se retira de uma coisa ou de uma atividade, e empregando-o em um sentido ainda mais traslato, significa a "vantagem". Entre o I e o II século a.c. fructus tem também um valor "subjetivo" ao lado do valor "objetivo" acima indicado: ou seja, indica não somente a "renda", como também o "gozo" como ação do sujeito.

(19) Cfr. F. GORIA, Schiavi. Sistematica delle persone e condizioni economico-sociali nel principato, in "Prospetive sistematiche nel diritto romano", Turim, 1976, 332. Esse paralelismo, contudo, entre os conceitos de persona e o conceito de homo vem a ser abalado quando o conceito de persona se amplia até compreender também a pessoa jurídica, i.é, um ente com capacidade jurídica diversa da do homem (cfr. P. CATALANO, Alle radici del problema delle persone giuridiche, in "Rassegna di Diritto Civile", 1983, 948: o autor, contudo, não usa a expressão "capacidade juŕ́dica", mas somente "ente"). Cumpre notar, ainda, que a expressão homo nas fontes jurídicas é usada muitas vezes não somente em relação ao homem em geral, mas também referindo-se à pessoa do escravo (cfr. B. ALBANESE, Le persone nel diritto privato romano, Palermo, 1979, 8 e Gai. II. 13). Com relação a essa terminologia, L. CAPOGROSSI-COLOGNESI, La denominazione degli schiavi e dei padroni nel latino del terzo e del secondo secolo a.C., in "Actes du colloque sur l'esclavage", Nieborow, 2-6.XII.1975, Vars6via, 1979, 177 ss., mais especificamente se referindo ao periodo do final da república, diz que na linguagem jurídica o escravo era denominado de três formas diversas: servus, mancipium e homo, sendo que é no Digesto que homo vem usado mais particularmente e com maior freqüência com relação ao escravo. Essa denominação, segundo o autor, possui uma ironia certamente involuntária, pois "afferma la radicale espropriazione del carattere umano dello schiavo nel momento stesso in cui sottolinea la natura comune che unisce lo schiavo all'uomo libero, entrambi indicati e concepiti come homines e quindi como realtà assolutamente diverse da qualsiasi altro bene o alto essere animato su cui possa costituirsi un diritto di proprietà. Já a denominação do escravo como mancipium, continua o a., remonta à época antiquissima e refleteria o fato que de todas as res mancipi seria o escravo a figura de maior relevo. 
sujeito de direitos, mas indica a condição humana, a pessoa como "homem", como "ser humano"(20). Assim, o conceito de homo se identifica com aquele de persona, e para Gaio o escravo é um homo, e portanto persona.

A condição humana do escravo vem também atestada nas fontes literárias do período tardo-republicano e do início da idade imperial. Sêneca, por exemplo, em uma carta a Lucílio (Ep. 47), na qual se referia ao tipo de relacionamento entre esse e seus escravos, insiste no ponto de que os escravos sâo seres humanos $^{(21)}$.

Significativa é a segunda parte do passo de Gaio, onde esse recorda a antiga disputa, sem contudo mencionar nomes. Vê-se claramente que o jurista se refere ao passado, já que usa videbatur ${ }^{(22)}$. Certamente no seu tempo a controvérsia já se encontrava superada. A motivação da regra absurdum enim videbatur hominem in fructu esse certamante é de caráter filosófico: cum omnes fructus rerum natura hominum gratia comparaverit ${ }^{(23)}$.

(20) G. GROSSO, Problemi sistematici nel diritto romano. Cose - contratti, sob os cuidados de L. LANTELLA, Turim, 1974, 7. V. também CATALANO, op. cit., 496. Sobre a evolução do termo persona, cfr. R. ORESTANO, Il problema delle persone giuridiche in diritto romano, Turim, 1968, 7 ss.

(21) Sen. epist. 47.1:

Libenter ex his, qui a te ueniunt, cognoui familiariter te cum seruis tuis uiuere: hoc prudentiam tuam, hoc eruditionem decet. "Serui sunt." Immo homines. "Serui sunt." Immo contubernales. "Serui sunt." Immo humiles amici. "Serui sunt." Immo conserui, si cogitaueris tantundem in utrosque licere fortunae.

Referindo-se a Sêneca, E. VOLTERRA, Istituzioni di diritto privato romano, Roma, 1980, 53, diz que a doutrina estóica ensinava que a escravidão não existia na natureza humana e que a condição de livre ou de servo eram devidas à sorte ou à injustiça, e, apesar de ressaltar tal ideal filos6fico frente à realidade de seu tempo, nâo podia contudo imaginar um ordenamento estatal que reconhecesse a todos os seres humanos personalidade jurídica. (Sobre a filosofia humanitária de Sêneca com relação aos escravos, cfr. M.T. GRIFFIN, Seneca. A philosopher in polities, Oxford, 1976, 256 ss.).

(22) TALAMANCA, op. cit., 321, nota 70, com relação a esse passo de Gaio comenta: "Come osservano il Basanoff e il Watson, Gaio vuole, infatti, riferire le ragioni in base alle quali si $\epsilon$ risolta, in un determinato senso, la disputa fra i veteres (preciso è il segnale dato a tale proposito da videbatur) e il giurista dell'età degli Antonini non fa che esplicitare quanto era detto - con una sintesi che, forse, sottintende in modo eccessivo il "background" filosofico - da Bruto, secondo quanto ne referisce Ulpiano in D. 7.1.68 pr. Onde, anche da questo punto di vista, si viene a riaffermare l'orientamento "filosofico" della motivazione del giurista repubblicano".

(23) Com relação à suspeita de serem os passos de Gaio, contidos nas suas Res cottidianae, trabalhos de feitura pós-clássica (do final do III séc. d.C.), ou mais especificamente uma versão ou elaboração das suas Institutas, e assim não ser o passo aqui tratado original desse jurista, cfr. SCHULZ, op. cit., 167 e TALAMANCA, op. cit., 321 , nota 70 . 
Já Ulpiano, à diferença de Gaio, é muito mais preciso, pois se refere claramente a Brutus: sed Bruti sententia optinuit fructuarium in eo locum non habere...(24). Segundo Talamanca, retomando Kaser ${ }^{(25)}$, a motivação de UIpiano (neque enim in fructu hominis homo esse potest) é na mesma ordem de idéias daquela que seria a de Brutus. Obscura, contudo, se apresenta essa motivação, cuja frase é de difícil compreensão. Qual o significado da afirmação "que o homem não pode ser considerado fruto de um outro homem"? Kaser é da opinião de que Brutus teria excluído que o partus ancillae fosse considerado um fruto porque era da mesma natureza da coisa frugífera. Assim considerado, contudo, também as crias dos animais não poderiam ser arroladas entre os frutos naturais, e, se Ulpiano retomasse Brutus, com essa argumentação soaria ilógico, já que do passo 17 ad Sab., D. 7.1.68.1 sabe-se que Ulpiano seguia a orientação da escola sabiniana, para a qual as crias dos animais eram de ser consideradas frutos ${ }^{(26)}$. Talamanca é da opinião que o principium do passo citado deixa transparecer uma consideração de ordem econômica por detrás da coloração filosófica ${ }^{(27)}$; consideração essa que se poderia extrair também de Ulp. 15 ad ed., D. 5.3.27 pr.:

Ancillarum etiam partus et partuum partus quamquam fructus esse non existimantur quia non temere ancillae eius rei causa comparantur ut pariant, augent tamen hereditatem...(28).

(24) Segundo SCHIAVONE op. cit., 27, no passo 17 ad Sab., D. 7.1 .68 pr., Ullpiano teria evidentemente encontrado referência em Sabino, que por sua vez já a teria tomado de Quinto Múcio.

(25) TALAMANCA, op. cit., 320, nota 69.

(26) Nota-se, todavia, que na hipótese na qual se deve proceder à summissio, as crias dos rebanhos também não são tratadas como frutos (cfr. Ulp. 17 ad Sab., D. 7.1.68.2 e D. 7.1.70.1). Sobre a opinião de KASER e corrente contrária, v. TALAMANCA, op. cit., 320, nota 70. A obscuridade da motivação dada por Ulpiano em D. 7.1.68 pr. e tal, que talvez por isso não fazem qualquer referência a ela os compiladores das Basilicas (cfr. 42.1.27); de outra parte nem mesmo a glosa a explica por completo.

(27) TALAMANCA, op. cit., 322, nota 72.

(28) Cfr. Ulp. 15 ad ed., D. 5.3.20.3 e Bas. 42.1.27. 
Trata-se nesse caso de uma hereditatis petitio, na qual se discutia se seria possível fazer parte do pedido de restituição, além da escrava-māe, também os seus partos. Segundo a regra geral da petição de herança, o possuidor deve restituir também os frutos. Ora, Ulpiano nesse passo faz uma exceção à regra partus ancillae in fructu non est, porque diz que apesar de o parto das escravas, bem como de o parto dos partos (netos), não serem frutos, fazem, contudo, parte da herança e assim podem ser reclamados. Equiparou, pois, o parto das escravas ao parto dos animais, que eram considerados frutos (cfr. Paul. 29 ad ed., D. 5.3.27). Respeitada aquela regra ao pé da letra, esses partos pertenceriam ao possuidor da escrava-mãe. A motivação que dá o jurista, nesse passo, ao fato de nāo serem frutos os partos da escrava é quia non temere ancillae eius rei causa comparantur ut pariant, ou seja, porque nem sempre se adquirem escravas com a finalidde de fazê-las procriar. Entendido non temere como "não sempre" emerge imediatamente uma consideração de ordem econômica na motivação de Ulpiano. Não toma ele uma razão de ordem filosófica dizendo, por exemplo, que não são considerados frutos por motivos humanitários. Pelo contrário, com aquela motivação admite que "também" para essa finalidade, isto é, a de aumentarem o número de filhos, vinham adquiridas as escravas. $E$ assim, obviamente, aumentam o patrimônio do proprietário ${ }^{(29)}$.

Talvez se possa tentar fundamentar o raciocínio de Ulpiano, analisando a situação econômica do período em que viveu.

Ulpiano foi jurista em um período que atravessou uma séria crise econômica - a famosa crise do III século - mais especificamente no campo monetário e no processo inflacionário. Ulpiano viveu entre 163 e 223 d.C. ${ }^{30)}$ e foi um "eminente giurista, altissimo funzionario, tutore del giovane imperatore Alessandro, senatore e, come lo definiscono i vecchi scrittori, imperii quasi colle-

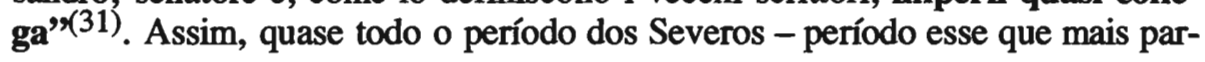

(29) Cfr. Paul. 33 ad ed., D. 19.1.21: tanto parece lógico que existia um motivo de alto interesse econômico na intenção de comprar escravas, para fazê-las reproduzirem, que ao comprador era dada a actio empti, caso fossem essas estéreis, fato este considerado vício redibitório. Com relação à interpretação de non temere no passo de Ulp. 15 ad ed., D. 5.3.27 pr., HEUMANN - SECKEL, Handlexikon zu den Quellen des römischen Rechts, Yena, 1907, 9 e., o traduz como "nicht leicht", isto $\epsilon$, "não facilmente", enquanto que nas Bas. 42.1.27 vem usada a expressão grega, cuja tradução em latim (cfr. HEIMBACH, Basilicorum libri, Lipsiae, IV, 1846, 221) vem como utique (que seria traduzido mais exatamente, como "não sempre", "não geralmente", "não habitualmente"). Cfr. também TALAMANCA, op. cit., 320 , nota 69.

(30) G. CRIFO, Ulpiano. Esperienze e responsabilità del giurista, in ANRW II/15, Berlin-Nova York, 739, diz que o momento do nascimento de Ulpiano oscila entre 163 e 170 d.C., enquanto que sua morte é de ser colocada entre 223 e 228 d.C.

(31) CRIFOे, op. cit., 738. 
ticularmente com referência ao reinado de Severo Alexandre, os históricos definiam como "um bloco de treze anos de poder... dominado pela prefeitura de Ulpiano até $228^{(32)}$ - esteve sob essa severa crise inflacionária que levou à tomada de drásticas medidas econômicas, como por exemplo a desvalorização da moeda em quase $50 \%$ do seu valor e o confisco de bens e de metais preciosos na Itália, Espanha e Gália por Septímio Severo, bem como a fixação de um limite de preços $^{(33)}$.

A inflação levou a um declínio da agricultura nesse período, que teve como uma das principais causas a insuficiência da força de trabalho. Essa insuficiência resultava da decadência do sistema escravagista, que contudo não encontrava mão-de-obra livre disponível, em número suficiente para substituir o trabalho-escravo. De Martino nota que ocorreu nesse período uma real diminuição da população livre e que - apesar da falta de fontes diretas e estatísticas sobre o assunto - Ulpiano mesmo se refere à penuria hominum desses $\operatorname{anos}^{(34)}$.

(32) CRIFÒ, op. cit., 764, claras são as palavras do autor que descrevem a real importância desempenhada pelos juristas, e mais particularmente por Ulpiano, no reinado dos Severos: "Vi si pud vedere, senza difficoltà, un vero programma generale di governo, reso noto a tutti gli amministrati (altro tratto degno di nota) e da ricondursi certamente alla cancelleria imperiale, cioè, nella sostanza, ai consiglieri del giovane principe, senatori e funzionari, uomini esperti nel diritto e famosi per la loro dottrina'. È possibile riconoscervi, insomma, la mano di Ulpiano".

(33) F. DE MARTINO, Storia economica di Roma antica, II, Florença, 1979, 364/5. Sobre a fixação de um limite de preços, que levou a uma maior penúria, o autor cita a fixação do preço de um escravo ex forma censoria na quantia de $\mathbf{5 0 0}$ denarii, preço esse baixo demais em uma época na qual devia haver exigência de mão-de-obra no mercado. Sobre a crise econômica do III séc., cfr. M. MAZZA, introdução à tradução italiana da obra de F. HEICHELHEIM, Storia economica del mondo antico, Bari, 1972, V ss.; Lotte sociali e restaurazione autoritaria nel III secolo d.C., Bari, 1973, 273 ss., sendo que nesta última obra MAZZA dá um quadro geral muito claro da situação econômico-social da época dos Severos. Período esse onde "scoppiarono le guerre civili, le lotte cioè tra le grandi unità militari delle province dell'impero, per imporre sul trono il loro candidato; esse portarono devastazioni e rovine, spogliazioni e rapine; e sullo sfondo insanguinato delle lotte militari, apparve profilarsi lo spettro della rovina economica dell'impero" (301).

(34) DE MARTINO, op. cit., 379. Com relaçāo à penuria hominum, cfr. Ulp. 4 off. proc., D. 50.6.3 (2-1): sabe-se tambem que esse foi um perfodo de grandes invasões, principalmente barbáricas, sendo que grande parte dos homens livres abandonavam o trabalho para integrar o exército. Além desse fator, sob o reinado de Marco Aurélio o exército foi atingido pela peste e esta se propagou por Roma, onde o número de mortos muitas vezes atingia 2.000 pessoas por dia (cfr. ibidem, 362). 
Se essa grave crise econômica foi fato que pode ter influenciado na decisão dos juristas da época severiana, não se pode, contudo, deixar de fazer aceno ao fato de que tais juristas tinham também formação filosófica, sendo que o pensamento jurídico dessa época sofre grande influência da filosofia grega: platônica, aristotélica e estóica. Os conceitos de ius naturale e de ratio naturalis não eram estranhos já à jurisprudência do II século, sendo que o maior testemunho é aquele de Gaio ${ }^{(35)}$. Na idade severiana, o direito natural encontra suas bases no pensamento sofista, como por exemplo naquele que diz que "todos os homens são livres". Afirmação essa que, segundo Bretone, era "sempre dissonante nel contesto economico-sociale del mondo antico"(36). Na realidade, a própria obra de Ulpiano reflete essa concepção do ius naturale, como direito concernente a todos os seres vivos e não somente aos homens. Assim, conclui Bretone, considerando-se "sacerdotes" e "filósofos", esses juristas reivindicam a si mesmos uma grande responsabilidade ética. No pensamento jurídico desse período se introduzem e amadurecem preocupações que até então não tinham sido trazidas à plena luz ${ }^{(37)}$.

Poder-se-ia, pois, dizer - com base nessa formação filosófica - que tanto Gaio quanto Ulpiano teriam tentado formular motivaçōes de ordem não econômico-jurídica, com relação à regra partus ancillae in fructu non est ${ }^{(38)}$. A nosso ver, contudo, seguindo essa linha de raciocínio, resultam ambos juristas pouco convincentes.

E é essa dificuldade de motivar filosoficamente tal regra que Ulpiano deixa transparecer em 17 ad Sab., D. 7.1.68 pr. Assim, devendo respeitá-la, já que era uma regra consolidada pela tradição jurídica, o jurista da época severiana tenta limitar ao máximo possível o seu âmbito de aplicação, fazendo men-

(35) M BRETONE, Tecniche e ideologie dei giuristi romani, Nápoles, 1982, 2 e., 32.

(36) BRETONE, op. cit., 33.

(37) BRETONE, op. cit., 34.

(38) GROSSO, Usufrutto e figure affini nel diritto romano, Turim, 1958, 202, diz, mais exatamente, que a motivação de Gaio, reproduzida nas Instituta de Justiniano, logicamente desenvolvida, deveria levar à condenar a própria escravidão. W.W. BUCKLAND, The roman law of slavery, 1908, 21, com relaçảo às motivaçōes dadas à regra de Brutus em D. 5.3.27 pr. e D. 22.1.28.1 expressa sua opinião no seguinte sentido: "Both of them express, somewhat obscurely the real reason, which was respect for human dignity, rather than any legal principle". 
ção a exceçōes ${ }^{(39)}$. Por outro lado, em 15 ad ed., D. 5.3.27 pr., recorre Ulpiano a um fundamento basicamente econômico, para justificar a mesmíssima regra.

Voltando a Brutus, sabemos qual era sua opinião, embora não nos informem as fontes em que termos foi elaborada sua motivação. E é exatamente essa motivação que os romanistas tentam precisar. A nosso ver, a análise do problema deve partir do estudo do contexto histórico do período no qual surge a disputa entre os juristas republicanos em torno do partus ancillae. No final do II século a.C. e início do I séc. a.C., nota-se em Roma um incremento significativo da população servil. Na realidade o número de escravos supera em quase o dobro do de homens livres ${ }^{(40)}$. A causa desse fenômeno é a expansão das atividades bélicas, que gerava um número elevado de prisioneiros. A essa fonte de escravidão somam-se os filhos nascidos de escravas (partus ancillae). Assim, o elemento servil representava uma grande parte da população e constituía quase que totalmente a mão-de-obra disponível. O trabalho escravo, portanto, se apresentava útil - e quase que totalmente imprescindível - em vários campos de atividades, tais como na área agrícola, no trabalho artesanal, em serviços adminstrativos, e muitas vezes até em trabalhos que exigiam conhecimento técnico especializado, já que muitos escravos provinham de culturas superiores e dotados de excelente instrução ${ }^{(41)}$. Na realidade, o trabalho servil eliminou quase que totalmente o trabalho livre em alguns setores ${ }^{(42)}$.

(39) Ulpiano em D. 5.3.27 pr., ao enunciar que os partos da escrava não eram considerados como fruto (... fructus esse non existimantur), usava a expressão existimantur, que tem um significado mais ameno do que afirmar fructus non sunt.

(40) VOLTERRA, op. cit., 53, nota que, segundo os historiadores modernos, enquanto nos primeiros séculos da República os servos eram uma pequena parte da população de Roma, no séc. III a.C. esse número havia sextuplicado. No séc. I a.C. na Itália frente aos 6 ou 7 milhões de homens livres havia 14 ou 13 milhöes de escravos, e que no século seguinte o número desses últimos deveria ainda ter aumentado. $\mathrm{Na}$ verdade, diz o autor, nos últimos séculos da República, devido à pirataria e à redução à condição de escravo de massas de habitantes das provincias, por motivo de dívida fiscal, desenvolveu-se um vasto comércio internacional de escravos. $E$, justamente, $o$ final do período republicano foi um período muito tumultuado por revoltas servis, fato que fatalmente levou os juristas da Epoca a revisarem os conceitos sobre a escravidão. Sobre a situação dos escravos no II séc. a.C., cfr. DUMONT, op. cit., 323 , nota 77 e S. TONDO, Crisi della repubblica e formazione del principato in Roma, Milão, 1988, 36 ss.

(41) TONDO, op. cit., 39 ss.

(42) Cfr. VOLTERRA, op. cit., 52 ss. e TONDO, op. cit., 38 ss. 
Juridicamente, contudo, a pessoa do escravo não encontrava quase que nenhum respaldo. Sendo privado de qualquer personalidade jurídica, era ele considerado uma res, objeto de relações jurídicas ${ }^{(43)}$, quase que totalmente reduzida a uma mercadoria como outra qualquer ${ }^{(44)}$. Essa situação tem como causa o número elevado da população servil, que deixa pois em plena evidência o caráter de propriedade, de "direito" do escravo com relação ao proprietário, já que o relacionamento afetivo entre eles, pessoal e individual, cada vez se dissolve mais nessa massa de $\operatorname{servos}^{(45)}$.

Destarte, chegamos ao final do II século a.C. com uma dramática situação social da população servil, situação essa que não poderia resistir por muito mais tempo, dando origem a uma série de rebeliōes que se desenrolaram entre $140 \mathrm{e}$ 70 a.C. ${ }^{(46)}$. Certamente Brutus não poderia ter permanecido insensível frente a um quadro de grandes e graves distúrbios sociais. Poder-se-ia dessa maneira

(43) VOLTERRA, op. cit., 54.

(44) TONDO, op. cit., 41, citando M. FINLEY, Schiavitù antica e ideologie moderne (1980), Bari, 1981, 91 ss., deixa bem clara a situação em que se encontravam os escravos: “... E, pertanto, in modo da raffigurarvi una riduzione a merce della persona dello schiavo (onde, per esempio, si parlava - sia pure in funzione critica - del trattare gli schiavi 'come se fossero delle scarpe o dei vasi') non soltanto della sua forza lavoro. Con consequenze tristementi coerenti - che giungevano a forme di straordinaria spietatezza anche agli effetti disciplinari e punitivi"'. Não se deve esquecer, por outro lado, que o escravo, enquanto homo, gozava de prerrogativas não reconhecidas a outros tipos de res, enquanto participava dos sacra; fazia tornar-se religioso o terreno onde vinha sepultado; podia ser destinatário de sançōes públicas; etc. (cfr. VOLTERRA, op. cit., 56 ss.). O escravo vivia às espesas do proprietário, não possuindo patrimônio próprio, com algumas exceções a ele era permitido formar um peculium. Esse patrimônio representado pelo peculium, contudo, juridicamente não pertencia ao escravo, passando ao seu proprietário quando aquele morria ao invés de se transferir aos seus descendentes. Mesmo porque, não sendo a união conjugal entre escravos considerada matrimônio, mas uma simples relação de fato (contubernium), esse não criava relações de parentesco (assim, a ele era negado até mesmo o direito de construir familia). O proprietário, por fim, tinha sobre o escravo poder de vida e de morte. Somente mais tarde foram estabelecidas regras impondo limitações à discricionariedade do poder do dono, bem como proibindo sevícias cruéis aos escravos e estabelecendo penas, caso fossem infringidas tais proibições.

(45) Cfr. CAPOGROSSI-COLOGNESI, Le forme giuridiche della schiavitù e la società romana nella tarda repubblica, in “Opus", Roma, 1982, I fasc. 1, 87.

(46) Cfr. TONDO, op. cit., 45. O diminuído valor dos escravos, a grande diferença de estirpe entre eles, bem como serem empregados em trabalhos muitas vezes longe da administração direta do proprietário, e o perigo que representava o seu elevado número (o que gerava contínuas revoltas), sendo que todos esses fatores somados levaram à modificação profunda da condição de fato do escravo, com inevitáveis conseqüências jurídicas, bem como à emanação de leis específicas com relaçâo à escravidão no início do Império (cfr. VOLTERRA, op. cit., 54). 
hipotizar que, atribuindo o parto ao nu-proprietário e negando-lhe o caráter de fruto, o jurista poderia ter atenuado - ao menos aparentemente - a qualidade de mero objeto de propriedade que representava fortemente a figura do escravo.

O problema, em suma, segundo nosso entendimento - sempre apoiado contudo em terreno meramente hipotético, dada a falta de testemunho direto das fontes - transcende a barreira dos princípios filosóficos e humanitários ${ }^{(47)}$ e poderia tranqüilamente avançar para o campo da problemática econômica, ou seja, dos jogos de interesse com relação ao valor patrimonial que representava o parto da escrava ${ }^{(48)}$. Tal argumentação, entretanto, nos coloca frente a várias indagações. Por que Brutus favorece a posição do nu-proprietário e não a do usufrutuário, já que havia entre eles um interesse econômico conflitante - e facilmente compreensível - pela propriedade desses novos escravos? Não se pode afirmar que foi uma tomada de posição a favor de uma classe dominante, já que

(47) TALAMANCA, op. cit., 322, nota 72, observa que Brutus e Gaio raciocinavam no campo filośfico, mas que outros bem poderiam ter feito a mesma coisa tomados da realidade econômica, e que tal hipotese é de fato atestada pelo passo de Ulpiano, 15 ad ed., D. 5.3.27 pr. Com relação à afirmação de certos autores, que conferem à decisão de Brutus um caráter de ordem humanitária, porque com a atribuição do parto ao dominus proprietatis, o fillho não vem separado da mãe logo após vir à luz, TALAMANCA, op. cit., 323, nota 77 (retomando observação de WATSON, Morality, slavery and the jurists in later roman republic, in "Tulane Law Review" 42, 1967-68, 293 ss.) observa que, pelo contrário, a atribuição do parto ao nu-proprietário comportava a imediata separação entre mãe e filho. Além do motivo acenado por TALAMANCA, nada impedia que o dominus alienasse mãe ou filho separadamente, já que sobre os seus bens podia dispor livremente.

(48) Não há dúvidas de que o escravo, em geral, representa um bem de alto valor econômico. Se já na época de Brutus - quando ocorreu um aumento elevadíssimo do número de escravos em Roma - esse valor patrimonial poderia ter sido motivo de influência na decisão do jurista republicano, muito mais facilmente se explicaria essa mesma tomada de posição por parte de Ulpiano, em cuja época a situação econômica era serifssima, agravada pela falta de mão-de-obra no mercado (vide supra notas 33 e 34).

(49) CAPOGROSSI-COLOGNESI, op. cit., 87, ensina que já no III séc. a.C. a sociedade romana era organizada em função do controle da res publica e fundada sobre a propriedade privada da terra, encontrando-se por outro lado, totalmente superado o modelo fundado sobre o ordenamento gentilício, isto $\epsilon$, de propriedade coletiva, do tipo doméstico, centralizado na figura do pater familias. E são os proprietários dessas terras privadas que formam uma nova aristocracia, cujo "sfruttamento dei propri possessi doveva essere ormai assicurata dalla presenza di un numero adeguato di schiavi". Sobre os latifúndios e a organização agrária romana, cfr. do mesmo autor a introdução a AA.VV., L'agricoltura romana - Guida storica e critica, Bari, 1982, VII ss. 
certamente tal conflito se apresentava no interior da mesma classe social, podendo em um caso concreto tanto nu-proprietário como usufrutuário serem os ricos proprietários de terras. É ainda de se perguntar se não se desenvolveu na estrutura escravagista romana, e em que nível, um interesse na "produção-demassa" de escravos, já que esses representavam as bases da organizacão das empresas agrárias, pertencentes aos proprietários de grandes terras ${ }^{(49)}$. Tais problemas, contudo, ultrapassam os limites da presente pesquisa, restando em aberto para uma posterior reflexão.

Por outro lado, contudo, conforme resulta das fontes retroexaminadas, Brutus não afirmou que em geral o parto da escrava não é um fruto, mas somente que não deve ser considerado como tal no âmbito do usufruto. Essa regra é pacificamente aceita pelos juristas sucessivos que nos são notícia da controvérsia e que tentam, por sua vez, formularem motivaçōes com coloração filosófica. Esses juristas, portanto, encontram dificuldades de legitimar e aplicar a outras situações o princípio geral segundo o qual o partus ancillae in fructu non est. Tal princípio certamente recebeu maior apoio e ressonância entre os filósofos. ${ }^{(50)}$

(50) Segundo M. KASER, Partus ancillae, in ZSS (1958), 197, este princípio gozava de escassa popularidade entre os juristas, mas, ocorre repetir que o princípio em questão, meramente filoś́fico, não se identifica com a regra jurídica introduzida por Brutus e limitada à hipótese do usufruto da escrava. 